\title{
Research on the Coordination of Protection Coupling of Ecological Environment and Tourism Development
}

\author{
Li Yang ${ }^{1, *}$, Pengcheng $\mathrm{Su}^{2}$ \\ ${ }^{1}$ Guilin University of Technology, Tourism Management, Guilin 541006, China \\ ${ }^{2}$ Xi'An Jiaotong University, Business Administration, Xi'an 710048, China
}

\begin{abstract}
While tourism has become a strategic pillar industry, adding vitality to regional development, ecological and environmental problems have become increasingly prominent. Based on the evaluation index system of ecological environment and tourism development, the paper takes Guangxi Zhuang Autonomous Region as an example and uses entropy weighting method to reduce the dimension of the original data. Then, the coupled coordination model is used to compare and analyse the comprehensive development index of the two systems from 2009 to 2018, as well as the development level of the coupling coordination degree between the systems. The results are as follows: (1) Ecological environment and tourism development are interrelated and mutually restricted, with positive and negative feedback. (2) The comprehensive development level of ecological environment system and tourism development system is generally on the rise. The coupling degree fluctuates between the two systems, but the coordination degree and the comprehensive development index show a trend of steady growth on the whole, which accords with the characteristics of high coupling and not high coordination. (3) Finally, according to the development of the coupled coordination model, some suggestions on future ecological environment and tourism development are put forward.
\end{abstract}

\section{Introduction}

The ecological environment is composed of land resources, water resources, biological resources, climate resources and other elements, and is a composite ecosystem related to the sustainable development of society and economy. A benign ecological environment is the cornerstone to support the healthy development of tourism and an important part of increasing tourism attractiveness. The development of tourism also provides a stable financial guarantee for the protection of the ecological environment. However, with tourism in full swing, it will inevitably cause damage to the ecological environment, and the environmental pollution and waste of resources in turn restrict the development of tourism. The two systems influence and restrict each other. As a famous karst topography in Guangxi, the contradiction between ecological environment protection and tourism development is particularly prominent because of the destructive nature of karst topography. Therefore, the tourism industry must be developed within the scope of the ecological environment, so as to realize the benign interaction and coordinated development of the tourism industry and the ecological environment.

\section{Domestic development}

The relationship between tourism development and ecological environment has always been a research hot topic of scholars at home and abroad. Domestic scholars mainly use a combination of quantitative and qualitative methods, and study the relationship between the two systems through the gray GM model, PSR model, and coupling coordination model. Wang(2009) explores the relationship between ecological environment and tourism development from the perspective of coupled tourism, and proposes a sustainable development feedback mechanism for Kanas scenic $\operatorname{spot}^{[1]}$. Chen(2019) studies the mechanism of ecotourism in poverty alleviation from the perspective of ecological anthropology ${ }^{[2]}$. Although there are a lot of studies on the relationship between ecological environment and tourism development, there are few studies from the perspective of ethnic minorities in Guangxi. Therefore, the study of the relationship and development level between the ecological environment and tourism development in minority areas also provides suggestions for ecological protection and low-carbon development in the area.

\section{Data collection and analysis}

\subsection{Data sources and processing}

Constructing an evaluation index system is an important foundation for studying the level of coupling and coordination between the ecological environment and tourism development in Guangxi Zhuang Autonomous Region. The ecological environment and tourism

\footnotetext{
* Corresponding author: 1033323577@qq.com
} 
development are two relatively complex systems, so the article selects the relevant indicators of the two systems based on the PRS model, the research results of relevant scholars and the existing mature research results ${ }^{[3-4]}$. The ecological environmental system index consists of two dimensions: the current situation of environmental pollution and the results of environmental governance. It covers 11 specific indicators and mainly reflects the environmental quality, pollution and governance of a region. The index of tourism development system is composed of two dimensions: tourism economy and tourism service, including eight specific indicators that mainly reflect the development advantage, scale and level of tourism. In order to ensure the authenticity, completeness and scientificity of the data, the data required by the two systems in the past ten years are selected from the 2009-2018 China Statistical Yearbook and the Guangxi Statistical Yearbook as samples. The coupling coordination model is used to further analyze the relationship between Guangxi's ecological environment and tourism industry.

In order to eliminate the difference in magnitude and dimension of the original data of the indicator, firstly, it is necessary to use the range method to perform dimensionless processing on each indicator data into categories, and then calculate the weight of the indicator according to the entropy weighting method and the analytic hierarchy process.

$$
\begin{aligned}
& X_{i j}^{,}=\frac{X_{i j}-\min \left(X_{i j}\right)}{\max \left(X_{i j}\right)-\min \left(X_{i j}\right)}+0.001 \\
& X_{i j}=\frac{\max \left(X_{i j}\right)-X_{i j}}{\max \left(X_{i j}\right)-\min \left(X_{i j}\right)}+0.001 \\
& H_{j}=-k\left(\sum_{i=1}^{m} P_{i j} \ln P_{i j}\right), k=\frac{1}{\ln m} \\
& P_{i j}=\left(1+X_{i j}\right) /\left(\sum_{i=z}^{m}\left(1+X_{i j}\right)\right) \\
& W_{j}=\left(1-H_{j}\right) /\left(\sum_{j=1}^{n}\left(1-H_{j}\right)\right)
\end{aligned}
$$

\begin{tabular}{|c|c|c|c|c|c|}
\hline System & Element & Index & Nature & Code & $\begin{array}{c}\text { Statistical } \\
\text { weight }\end{array}$ \\
\hline \multirow{11}{*}{$\begin{array}{c}\text { Ecological } \\
\text { environment } \\
\text { system }\end{array}$} & \multirow{5}{*}{$\begin{array}{c}\text { The current } \\
\text { situation of } \\
\text { environmental } \\
\text { pollution } \\
(0.2605)\end{array}$} & Volume of industrial solid waste product/ 10,000 tons & - & $\mathrm{X}_{1}$ & 0.0570 \\
\hline & & $\begin{array}{c}\text { Volume of industrial waste water discharged } / 10,000 \\
\text { tons }\end{array}$ & - & $\mathrm{X}_{2}$ & 0.0501 \\
\hline & & $\begin{array}{c}\text { Volume of industrial waste gas discharged/100 million } \\
\text { cu.m }\end{array}$ & - & $\mathrm{X}_{3}$ & 0.0478 \\
\hline & & Volume of sulfur dioxide discharged/10,000 tons & - & $\mathrm{X}_{4}$ & 0.0512 \\
\hline & & Total energy consumption/10,000 tce & - & $\mathrm{X}_{5}$ & 0.0557 \\
\hline & \multirow{6}{*}{$\begin{array}{c}\text { The results of } \\
\text { environmental } \\
\text { governance } \\
(0.2921)\end{array}$} & Public green space of parks per population $/ \mathrm{m}^{2}$ & + & $\mathrm{X}_{6}$ & 0.0540 \\
\hline & & Coverage area of forestation of developed area $/ \%$ & + & $\mathrm{X}_{7}$ & 0.0489 \\
\hline & & Rate of garbage no harmful disposal $/ \%$ & + & $\mathrm{X}_{8}$ & 0.0443 \\
\hline & & Treatment rate of polluted water $/ \%$ & + & $\mathrm{X}_{9}$ & 0.0452 \\
\hline & & $\begin{array}{l}\text { Volume of comprehensive utilization of industrial } \\
\text { solid waste/10,000 tons }\end{array}$ & + & $\mathrm{X}_{10}$ & 0.0463 \\
\hline & & $\begin{array}{c}\text { Energy saving and environmental protection capital } \\
\text { investment / } 100 \text { million yuan }\end{array}$ & + & $\mathrm{X}_{11}$ & 0.0553 \\
\hline \multirow{8}{*}{$\begin{array}{c}\text { Tourism } \\
\text { development } \\
\text { system }\end{array}$} & \multirow{4}{*}{$\begin{array}{l}\text { Tourism } \\
\text { economy } \\
(0.2367)\end{array}$} & Number of inbound tourists/10,000 people & + & $\mathrm{X}_{12}$ & 0.0531 \\
\hline & & $\begin{array}{c}\text { International tourism/foreign exchange income/ten- } \\
\text { thousand dollars }\end{array}$ & + & $\mathrm{X}_{13}$ & 0.0552 \\
\hline & & Number of domestic tourists/10,000 person-times & + & $\mathrm{X}_{14}$ & 0.0616 \\
\hline & & Domestic tourism revenue/100 million yuan & + & $\mathrm{X}_{15}$ & 0.0624 \\
\hline & \multirow{4}{*}{$\begin{array}{l}\text { Tourism } \\
\text { service } \\
(0.2107)\end{array}$} & Total number of travel agencies & + & $\mathrm{X}_{16}$ & 0.0555 \\
\hline & & Total number of star-rated hotels & + & $\mathrm{X}_{17}$ & 0.0487 \\
\hline & & $\begin{array}{c}\text { Business revenue of enterprises above designated size } \\
\text { of catering services } / 10,000 \text { yuan }\end{array}$ & + & $\mathrm{X}_{18}$ & 0.0546 \\
\hline & & $\begin{array}{c}\text { Business revenue of enterprises above designated size of } \\
\text { hotels } / 10,000 \text { yuan }\end{array}$ & + & $\mathrm{X}_{19}$ & 0.0532 \\
\hline
\end{tabular}

Among these formulas, $\mathrm{X}_{\mathrm{ij}}$ represents standardized data; $\mathrm{P}_{\mathrm{ij}}$ represents the proportion of the numerical value; $\mathrm{W}_{\mathrm{j}}$ represents the statistical weight of the jth index.

Table1. Evaluation Index System

\subsection{Research Methods}

$$
\begin{aligned}
& U_{i=1,2}=\sum_{j=1}^{n} W_{j} X_{i j} \\
& \lambda=U_{1} / U_{2}
\end{aligned}
$$

$$
\begin{aligned}
& C=\sqrt{\frac{U_{1} * U_{2}}{\left(\left(U_{1}+U_{2}\right) / 2\right)^{2}}} \\
& T=\alpha U_{1}+\beta U_{2} \\
& D=\sqrt{C * T}
\end{aligned}
$$

$\mathrm{C}$ is the coupling degree, the value range is $(0,1)$, the closer 
the $\mathrm{C}$ value is to 1 , the better the coupling degree of the two systems. $T$ is a comprehensive evaluation index; $\alpha, \beta$ are both undetermined coefficient, considering that tourism development and ecological environment are mutually complementary and equally important, and $\alpha+\beta=1$, so both take the value 0.5 .

\subsection{Data analysis}

\subsubsection{Overall analysis}

Table2. Comprehensive development index and coupling coordination

\begin{tabular}{|c|c|c|c|c|c|c|}
\hline Year & $\mathbf{U}_{\mathbf{1}}$ & $\mathbf{U}_{\mathbf{2}}$ & $\mathbf{C}$ & $\mathbf{T}$ & $\mathbf{D}$ & Grade \\
\hline 2009 & 0.1628 & 0.0385 & 0.7863 & 0.1006 & 0.2813 & mild disorder \\
\hline 2010 & 0.1334 & 0.1111 & 0.9958 & 0.1222 & 0.3489 & moderate disorder \\
\hline 2011 & 0.1008 & 0.2239 & 0.9254 & 0.1623 & 0.3876 & moderate disorder \\
\hline 2012 & 0.0851 & 0.3533 & 0.7911 & 0.2192 & 0.4164 & near disorder \\
\hline 2013 & 0.0908 & 0.3856 & 0.7855 & 0.2382 & 0.4325 & near disorder \\
\hline 2014 & 0.1131 & 0.4205 & 0.8174 & 0.2668 & 0.4670 & near disorder \\
\hline 2015 & 0.1466 & 0.4810 & 0.8463 & 0.3138 & 0.5153 & barely disorder \\
\hline 2016 & 0.1941 & 0.5258 & 0.8875 & 0.3600 & 0.5652 & barely disorder \\
\hline 2017 & 0.1861 & 0.5961 & 0.8516 & 0.3911 & 0.5771 & barely coordination \\
\hline 2018 & 0.1506 & 0.6835 & 0.7693 & 0.4171 & 0.5664 & barely coordination \\
\hline
\end{tabular}

According to Table 2 and Figure 1, it can be found that the development trend of the two systems can be roughly divided into two stages. The first stage: ecological environment composite index from 2009 to 2010 is higher than the tourism industry. This shows that at this stage, Guangxi Zhuang Autonomous Region has a stable and good ecological environment and a thriving tourism industry, which can fully rely on a good natural ecological environment and strong tourist attraction to win the favor of a large number of tourists. The high ecological environment index is because Guangxi's tourism industry mainly relies on the region's rich tourism resources and cultural ecological environment, which is an important basis for realizing tourism as a strategic pillar industry. The relatively sluggish tourism industry was mainly affected by the international financial crisis in 2008 and the unexpected events. In this period, the government and the society are more inclined to protect Guangxi's green wealth than to pursue the economic benefits brought by tourism.

In the second stage, the tourism industry composite index from 2011 to 2018 is significantly higher than the ecological environment composite index, and there is a gap between the comprehensive evaluation values of the two systems. The tourism development index has increased rapidly from 0.2239 to 0.6835 . With the support of local governments' policies to promote tourism development, the tourism industry has witnessed a spurt
According to the correlation model of coupling degree, the comprehensive evaluation indexes $\mathrm{U}_{1}$ and $\mathrm{U}_{2}$ of ecological environment and tourism development of Guangxi Zhuang Autonomous Region from 2009 to 2018, as well as the coupling degree $\mathrm{C}$, system comprehensive evaluation index $\mathrm{T}$ and coupling coordination degree $\mathrm{D}$ between the two systems are obtained respectively. The coupling coordination level of each year is divided according to the "tenths method" proposed by Liao ${ }^{[5]}$. of development. The ecological environment composite index drops from 0.1008 in 2011 to 0.0908 in 2013, which indicates that the development of tourism in the past three years has caused damage to the ecological environment and brought about negative effects. The ecological environment index in 2014 begins to rise again, but in the following two years it begins to decline again. Generally speaking, the comprehensive evaluation index of ecological environment is always less than 0.5 , and the overall ecological environment quality is not high, so its protection needs to be strengthened. Moreover, in the second stage of development, it can be found that the growth rate of the tourism industry is significantly higher than that of the ecological environment. Therefore, in the following regional development, attention should be paid to the actual situation and existing problems of the ecological environment, as well as the restoration and protection of ecological resources.

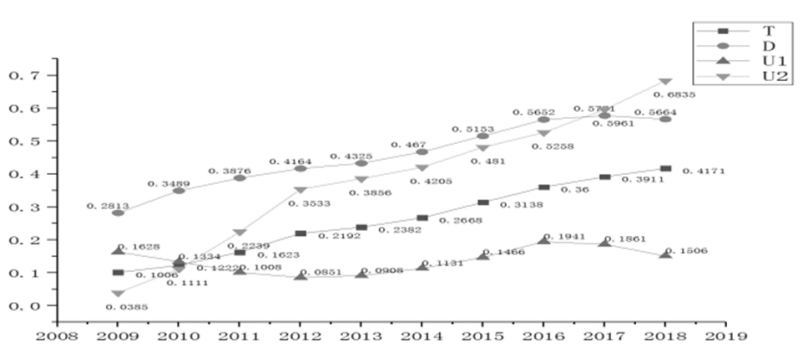

Fig1. Index Development Trend Chart

Table3. Comprehensive development index and coupling coordination

\begin{tabular}{|c|c|l|}
\hline Year & $\lambda$ & \multicolumn{1}{c|}{ Type characteristics } \\
\hline 2009 & 4.2286 & Ecological environment is ahead of tourism development, the two are at low level coupling stage \\
\hline 2010 & 1.2007 & Ecological environment is ahead of tourism development, the two are highly antagonistic. \\
\hline 2011 & 0.4502 & Tourism development is ahead of ecological environment, the two are highly antagonistic. \\
\hline 2012 & 0.2409 & Tourism development is ahead of ecological environment, and the two are at a low level. \\
\hline 2013 & 0.2355 & Tourism development is ahead of ecological environment, and the two are at a low level. \\
\hline 2014 & 0.2690 & Tourism development is ahead of ecological environment, and the two are at a low level. \\
\hline
\end{tabular}




\begin{tabular}{|l|l|l|l|}
\hline 2015 & 0.3048 & Tourism development is ahead of ecological environment, and the two are in the run-in stage. \\
\hline 2016 & 0.3692 & Tourism development is ahead of ecological environment, and the two are in the run-in stage. \\
\hline 2017 & 0.3122 & Tourism development is ahead of ecological environment, and the two are in the run-in stage. \\
\hline 2018 & 0.2203 & Tourism development is ahead of ecological environment, and the two are in the run-in stage. \\
\hline
\end{tabular}

According to Table 3, the ecological environment development system in Guangxi from 2009 to 2010 is ahead of the tourism industry system, and the two systems develop from low-level coupling stage to run-in stage. From 2011 to 2018, the tourism industry development system is ahead of the ecological environment system. The two systems transition from the antagonistic stage to the run-in stage, and there is still a great space for improvement from the coordinated development level. This also shows that the ecological environment of Guangxi cannot support the development of tourism industry well.

\section{Conclusion and suggestions}

\subsection{Conclusion}

In this paper, the coupled coordination degree model is used to analyze the evolution of the ecological environment and the coordination level of tourism development in Guangxi Zhuang Autonomous Region, so as to analyze the coordination relationship between the two systems.

(1) From the perspective of the coupling level, the two systems of ecological environment and tourism development are closely linked and have strong mutual coupling. The ecological environment lays a rich resource and material foundation for the development of tourism. While the tourism industry takes advantage of the development of ecological resources, it will also profoundly affect the ecological environment. The ecological environment and tourism development in Guangxi Zhuang Autonomous Region are on an upward trend. The comprehensive environment of the ecological environment is relatively good and the development level is relatively high. With the continuous development of the local unique ecological environment advantages, the tourism industry is developing rapidly.

(2) From the perspective of the coordination stage, the coupling development stage of the ecological environment and tourism development in Guangxi from 2009 to 2018 has improved from the initial moderate disorder to primary coordination. And the development type passes through antagonistic stage to running-in stage. However, the development of the two systems accords with the characteristics of high coupling and low coordination. Although the coupling degree is stable and high, the overall coupling coordination degree is low, failing to reach the ideal state, and there is still a large space for high-quality coordinated development.

\subsection{Suggestions}

\author{
4.2.1 Improving the carrying capacity of the \\ ecological environment
}

The healthy and sustainable development of tourism depends on a good regional ecological environment, which is diverse and dynamic. Therefore, it is necessary to increase the carrying capacity within a reasonable range according to the specific conditions of different cities in Guangxi Zhuang Autonomous Region. Taking sustainable development and the "Two Mountains Theory" as the guiding concept, it adopts differentiated and long-term solutions, adheres to the coordinated development of the ecological environment and tourism, and forms a complex ecosystem of economic and natural ecological virtuous cycles.

\subsubsection{Improve the quality of coupling coordination}

When developing the tourism industry in Guangxi, it should not only be based on the favorable ecological advantages in the region, accelerate the green transformation and development of the tourism industry, but also pay attention to the steady advancement of the development of the ecological environment. The region must adhere to the coordinated development of the ecological environment and tourism.

\section{References}

1. Wang H, Yang Z P, Hang F. Research on Kanasi Lake's "Tourism-environment" Coupling Pattern Under Water Environment Stress[J]. Journal of Huazhong Normal University,43(2009):345-349.

2. Chen H P. Study on the Eco-tourism Poverty Alleviation in Minority Areas from the Perspective of Ecological Anthropology: Taking Zhongdong Miao Village in Guizhou Province as an Example[J]. Guizhou Ethnic Studies, 40(2019):139-145.

3. Gao N, Ma Y F, Li T S. Study on the Coordinative Development between Tourism Industry and Urbanization Based on Coupling Model: A Case Study of Xi'an[J]. Tourism Tribune, (2013):62-68.

4. Fang Y L, Huang Z F, Duan Z X. Coupling and Coordinating about Chinese Tourism Developing and Eco-Environment[J]. Economic Geography, 33(2013):195-201.

5. Liao C B. Quantitative Judgement and Classification System for Coordinated Development of Environment and Economy--A Case Study of the City Group in the Pearl River Delta[J]. Tropical Geography,3(1996):3-5. 